\title{
DEVERES ESTATAIS DE PROTEÇÃO DA FAUNA E DIREITO FUNDAMENTAL DE LIVRE EXERCÍCIO DE CULTO: O CASO DO RECURSO EXTRAORDINÁRIO 494.601
}

\author{
STATE DUTIES OF FAUNA PROTECTION AND FREEDOM OF WORSHIP: EXTRAORDINARY \\ APPEAL 494.601 IN THE FULL BENCH OF THE FEDERAL SUPREME COURT
}

Wilson Steinmetz ${ }^{1}$

Resumo: Examinam-se criticamente dois votos proferidos no Recurso Extraordinário 494.601, cujo julgamento está em andamento no Supremo Tribunal Federal. O objetivo é apontar os equívocos interpretativos e argumentativos no exame de constitucionalidade de norma legal estadual que excepcionou os cultos e liturgias de origem africana da proibição de tratamento cruel contra animais. Conclui-se que não há norma constitucional e legal que proíbe o sacrífico de animais em cultos religiosos, contudo é vedado o tratamento cruel contra animais para todos, inclusive no exercício de culto. Palavras-chave: Fauna. Tratamento cruel contra animais. Sacrifício de animais. Liberdade de culto.
Abstract: Two votes given in Extraordinary Appeal 494,601, whose judgment is pending in the Federal Supreme Court, are examined critically. The objective is to point out the interpretative and argumentative misunderstandings in the constitutional examination of a state legal norm that excepted the cults and liturgies of African origin from the prohibition of cruel treatment against animals. It is concluded that there is no constitutional and legal norm that prohibits the sacrificial of animals in religious cults, however, it is forbidden cruel treatment against animals for all, including in the exercise of worship.

Keywords: Fauna. Cruel treatment of animals. Sacrifice of animals. Freedom of worship.

Data de submissão: 03 de janeiro de 2019 Aceito em: 18 de fevereiro de 2019

\footnotetext{
Doutor e Mestre em Direito pela Universidade Federal do Paraná; Professor no Programa de Pós-Graduação em Direito da Universidade de Caxias do Sul e no Programa de Pós-Graduação em Direito da Universidade do Oeste de Santa Catarina; wilson.steinmetz@gmail.com; http://orcid.org/0000-0003-0519-6201
} 


\section{Introdução}

A Constituição do Brasil de 1988 atribuiu posição especial aos deveres estatais de defesa e proteção do meio ambiente ecologicamente equilibrado. Esses deveres se projetam sobre todos os âmbitos que compõem o meio ambiente. No que toca à fauna, há um princípio de proteção da fauna, como norma abrangente que abarca as mais diversas questões relativas à proteção dos animais, e há uma norma de conteúdo específico que proíbe a crueldade contra os animais. ${ }^{2}$

Em vários casos nos últimos anos, o Supremo Tribunal Federal (STF) pode interpretar e aplicar as normas constitucionais protetivas da fauna, especialmente a regra da proibição de tratamento cruel a animais. Citem-se o caso da Farra do Boi (RE 153531), os casos de Rinha de Galo (ADI 2514, ADI 3776 e ADI 1856) e o caso da Vaquejada (ADI 4983). Em todos esses casos, examinaram-se práticas culturais enraizadas em tradições populares à luz das normas constitucionais protetivas da fauna.

O Recurso Extraordinário 494.601 - doravante RE 494.601 - oportunizou mais uma vez ao STF a análise e interpretação do sentido e alcance das normas constitucionais protetivas da fauna, desta feita em face do direito fundamental ao livre exercício de culto, do princípio do Estado laico e do princípio da isonomia.

Passados quase doze anos de interposição do RE, em 2018 o Pleno do STF iniciou o julgamento do caso. Votaram os ministros Marco Aurélio (relator) e Edson Fachin. O julgamento foi suspenso com um pedido de vista do ministro Alexandre de Moraes.

O objetivo deste estudo é fazer um comentário crítico aos votos proferidos. Como se verá, ambos os votos são passíveis de objeções nas questões substantivas do caso.

\section{Fatos e histórico processual}

O Estado do Rio Grande do Sul, por meio da Lei 11.915, de 21 de maio de 2003, instituiu o Código Estadual de Proteção aos Animais (CEPA). O Código estabelece normas de proteção aos animais com o objetivo de "compatibilizar o desenvolvimento socioeconômico com a preservação ambiental." (art. $1^{\circ}$ ). Nesse sentido, é uma política pública de proteção do direito ao meio ambiente ecologicamente equilibrado instituído no art. 225 da Constituição do Brasil (CB).

$\mathrm{O}$ art. $2^{\circ}$ do CEPA prescreve a proibição de inúmeras condutas que atentam contra a integridade física e o bem-estar dos animais. ${ }^{3}$ Trata-se de normas que vedam práticas de crueldade contra os animais.

$\overline{2} \mathrm{CB}$, art. 225, "\$ $1^{\circ}$ Para assegurar a efetividade desse direito, incumbe ao Poder Público: [...] VII - proteger a fauna e a flora, vedadas, na forma da lei, as práticas que coloquem em risco sua função ecológica, provoquem a extinção de espécies ou submetam os animais a crueldade." (grifo nosso).

3 Art. $2^{\circ}$ - É vedado: I - ofender ou agredir fisicamente os animais, sujeitando-os a qualquer tipo de experiência capaz de causar sofrimento ou dano, bem como as que criem condições inaceitáveis de existência; II - manter animais em local com- 
Em 22 de julho de 2004, o Estado do Rio Grande do Sul, por meio da Lei 12.131, acrescentou um parágrafo único ao art. $2^{\circ}$ do CEPA: "Não se enquadra nessa vedação o livre exercício dos cultos e liturgias de matriz africana." Assim, a lei estabelece uma relevante exceção, excluindo os cultos e as liturgias de matriz africana da incidência das proibições dos incisos do art. $2^{\circ}$.

No mesmo ano de 2004, publicou-se o Decreto 43.252, regulamentando o art. $2^{\circ}$ do CEPA. O Decreto prescreve que "Para o exercício de cultos religiosos, cuja liturgia provém de religiões de matriz africana, somente poderão ser utilizados animais destinados à alimentação humana, sem utilização de recursos de crueldade para a sua morte." (art. $2^{\circ}$ ). Note-se que o decreto reinterpreta o conteúdo e o alcance do parágrafo único acrescentado pela Lei 12.131 ao art. $2^{\circ}$ do CEPA, a ponto de anular os seus efeitos. $O$ decreto restabelece a incidência das proibições do art. $2^{\circ}$ (caput e incisos) para todos os destinatários da lei, inclusive para cultos e liturgias: é vedado o sacrifício cruel de animais.

O Procurador-Geral de Justiça propôs Ação Direta de Inconstitucionalidade (Processo 70010129690) junto ao Tribunal de Justiça do Estado do Rio Grande do Sul contra a Lei Estadual 12.131/2004, que acrescentou o parágrafo único ao art. $2^{\circ}$ da Lei Estadual 11.915/2003 (CEPA). Argumentou que a Lei 12.131 é formal e materialmente inconstitucional. No plano formal, a lei invadiu competência privativa da União para legislar sobre matéria penal. No plano material, ao excluir da incidência do art. $2^{\circ}$ do CEPA apenas os cultos e liturgias de matriz africana, a Lei 12.131 violou o princípio da isonomia.

Por maioria, o Tribunal de Justiça julgou improcedente a Ação Direta de Inconstitucionalidade (ADI). Entre outros argumentos, para o Tribunal "[...] não há norma que proíba a morte de animais, e, de toda sorte, no caso a liberdade de culto permitiria a prática." No entanto, a maioria do Tribunal pontuou que é permitido o sacrifício de animais, "desde que sem excessos ou crueldade." Assim, a decisão do Tribunal é ambígua. De um lado, declara a constitucionalidade da exceção introduzida ao art. $2^{\circ}$ do Código pela Lei 12.131; de outro, exclui os (eventuais) excessos ou crueldade. Veja-se, no entanto, que é exatamente este o propósito do art. $2^{\circ}$, e respectivos incisos, do CEPA: proibir tratamento cruel contra animais. É uma decisão inconsistente.

Contra a decisão do Tribunal de Justiça, o Procurador-Geral de Justiça interpôs recurso extraordinário junto ao Supremo Tribunal Federal, com fundamento no art. 102, III, a, da Constituição do Brasil (CB). Alegou que o acordão do Tribunal de Justiça violou o inciso I do art. 22, o caput do art. $5^{\circ}$ e o inciso I do art. 19, todos da Constituição do Brasil. O recurso foi distribuído ao ministro Marco Aurélio.

pletamente desprovido de asseio ou que lhes impeçam a movimentação, o descanso ou os privem de ar e luminosidade; III - obrigar animais a trabalhos exorbitantes ou que ultrapassem sua força; IV - não dar morte rápida e indolor a todo animal cujo extermínio seja necessário para consumo; V - exercer a venda ambulante de animais para menores desacompanhados por responsável legal; VI - enclausurar animais com outros que os molestem ou aterrorizem; VII - sacrificar animais com venenos ou outros métodos não preconizados pela Organização Mundial da Saúde - OMS -, nos programas de profilaxia da raiva. 


\section{Questões constitucionais}

Caso apresenta três questões constitucionais. A primeira é de natureza formal: lei estadual que dispõe sobre tratamento cruel contra animais viola a competência legislativa privativa da União em matéria penal?

No caso, a Lei 12.131, ao excepcionar os cultos e liturgias de matriz africana das proibições de tratamento cruel ou maus tratos a animais, teria incursionado em matéria penal, cuja competência privativa para legislar é constitucionalmente expressa da União (CB, art. 22, I)?

Há duas outras questões de natureza material ou substantiva. Uma delas pode ser assim formulada: lei estadual que proíbe sacrifício de animais de formal geral, incluindo sacrifícios em rituais religiosos com eventual crueldade, viola a liberdade de crença e o livre exercício de culto? A outra: lei estadual que excepciona cultos e liturgias da vedação de sacrifício de animais com eventual tratamento cruel viola o princípio da isonomia e o princípio do Estado laico?

Neste estudo de caso, examino as questões substantivas.

\section{Fundamentos dos votos dos ministros Marco Aurélio e Edson Fachin}

O Recurso Extraordinário 494.601 - doravante RE 494.601 - foi distribuído em 29.09.2006. A relatoria coube ao ministro Marco Aurélio, que recebeu os autos conclusos em 02.10.2006. Em despacho de 03.11.2016 (publicado 05.11.2016), o relator recomenda que o recurso seja julgado pelo Pleno do Supremo Tribunal Federal:

O tema versado neste extraordinário definir se lei estadual poderia autorizar o sacrifício de animais em rituais de religiões de matriz africana é de relevância ímpar, sendo recomendável o julgamento pelo Plenário. Aciono o Regimento Interno e afeto a apreciação deste recurso extraordinário ao Pleno.

Faltando menos de dois meses para completar doze anos de interposição, o RE é levado a julgamento do Pleno em 09.08.2018. Votaram os ministros Marco Aurélio (relator) (RIO GRANDE DO SUL, 2018a) e Edson Fachin (RIO GRANDE DO SUL, 2018b). O julgamento foi interrompido com o pedido de vista dos autos feito pelo ministro Alexandre de Moraes.

O ministro Marco Aurélio julgou parcialmente procedente o recurso extraordinário. Atribuiu ao parágrafo único do art. $2^{\circ}$ da Lei n ${ }^{\circ}$ 11.915/2003 - acrescentado pela Lei 12.131/2004 -, do Estado do Rio Grande do Sul, interpretação conforme à Constituição do Brasil, no sentido de que é constitucional "[...] o sacrifício de animais em ritos religiosos de qualquer natureza, vedada a prática de maus-tratos no ritual e condicionado o abate ao consumo da carne." O ministro Edson Fachin julgou totalmente improcedente o recurso extraordinário. 


\subsection{Competência legislativa}

Ambos os ministros afastam a inconstitucionalidade da lei por violação ao inciso I do art. 22 da Constituição do Brasil. O CEPA não é lei penal. Assim, não excepciona a incidência de normas previstas na Lei federal 9.605/1998, como é o caso das previstas no art. 32.4

De fato, nesse ponto, é correta a interpretação dos ministros. Não se trata de lei penal, mas de lei que se projeta no âmbito da atuação administrativa do Estado. O propósito é promover a defesa da fauna com instrumentos administrativos. Essa é uma obrigação do Poder Público de todos os entes da Federação (CB, art. 225, VII). Ademais, o Estado tem competência, no âmbito da legislação concorrente, para editar normas sobre a fauna (CB, art. 24, VI).

É verdade que se poderia examinar a necessidade das prescrições contidas no art. $2^{\circ}$ do CEPA, haja vista práticas de crueldade contra animais serem vedadas por atos normativos federais, nos campos do direito penal e do direito administrativo sancionador (art. 32 da Lei 9.605/1998 e art. 29 do Decreto 6.514/2008, respectivamente). Contudo, aqui esse exame não é objeto. Circunscrevome ao campo das questões substantivas de interpretação constitucional.

\subsection{Princípio da isonomia e Estado Laico}

O ministro Marco Aurélio (RIO GRANDE DO SUL, 2018a) argumenta que uma interpretação (literal) do dispositivo impugnado (parágrafo único do art. $2^{\circ}$ do CEPA) que excepcione o sacrifício de animais apenas aos cultos e às liturgias de matriz ou origem africana viola o princípio da isonomia e o princípio da laicidade do Estado (CB, art. $5^{\circ}$, caput e art. 19, I, respectivamente). Com essa prescrição, o Estado está, simultaneamente, discriminando outras crenças que também sacrificam animais em seus cultos e suas liturgias e concedendo vantagem ou deferência a um tipo particular de crença. Daí por que propõe provimento parcial do recurso extraordinário, preservando o dispositivo da lei, mas com uma interpretação conforme à Constituição no sentido de que é constitucional "[...] o sacrifício de animais em ritos religiosos de qualquer natureza, vedada a prática de maus-tratos no ritual e condicionado o abate ao consumo da carne."

Para o ministro Edson Fachin (RIO GRANDE DO SUL, 2018b), o parágrafo único do art. $2^{\circ}$ do CEPA não viola o princípio constitucional da isonomia nem o princípio da laicidade do Estado brasileiro. Ao contrário, promove a liberdade religiosa e os direitos culturais de grupos que historicamente são objeto de preconceito e estigmatização. Edson Fachin traz um elemento novo à

\footnotetext{
4 "Art. 32. Praticar ato de abuso, maus-tratos, ferir ou mutilar animais silvestres, domésticos ou domesticados, nativos ou exóticos: Pena - detenção, de três meses a um ano, e multa. $\int 1^{\circ}$ Incorre nas mesmas penas quem realiza experiência dolorosa ou cruel em animal vivo, ainda que para fins didáticos ou científicos, quando existirem recursos alternativos. $\$ 2^{\circ} \mathrm{A}$ pena é aumentada de um sexto a um terço, se ocorre morte do animal."
} 
análise do caso: a prática de sacrifícios de animais como manifestação cultural constitucionalmente protegida (direito à cultura ou direitos culturais).

\section{Comentários e exame crítico}

Este caso envolve a interpretação e aplicação de várias normas constitucionais: o princípio da proteção da fauna, a regra da proibição de tratamento cruel contra animais, o princípio da liberdade de crença, o princípio do livre exercício de culto e o princípio do Estado laico.

As prescrições do caput e incisos do art. $2^{\circ}$ da Lei 11.915/2003 (CEPA) do Estado do Rio Grande do Sul vêm ao encontro do princípio constitucional da proteção à fauna e da regra da proibição de tratamento cruel contra os animais, ambas as normas enunciadas no inciso VII do art. 225 da Constituição do Brasil. E o desenho constitucional de repartição de competências da Federação confere aos Estados, no âmbito da legislação concorrente, o poder de legislar sobre a fauna (CB, art. 24, VI), desde que observados os limites da moldura estabelecida por normas gerais da União $\left(\mathrm{CB}\right.$, art. 24, $\left.\int 1^{\circ}\right)$.

A controvérsia constitucional tem por objeto o parágrafo único acrescentado ao art. $2^{\circ}$ pela Lei 12.131/2004: "Não se enquadra nessa vedação o livre exercício dos cultos e liturgias das religiões de matriz africana."

O significado desse dispositivo no contexto do art. $2^{\circ}$ é claro: as proibições prescritas nos incisos do art. $2^{\circ}$ não se aplicam ao uso de animais nos cultos e liturgias de religiões de origem africana. Os incisos do art. $2^{\circ}$ tipificam e vedam inúmeras práticas de crueldade e maus-tratos a animais. Logo, na hipótese de haver práticas cruéis e de maus-tratos a animais em cultos e liturgias de matriz africana, não há ilícito administrativo. Em uma primeira aproximação interpretativa, a norma do parágrafo único em questão é materialmente incompatível com as normas previstas no inciso VII do art. 225 da Constituição do Brasil.

Além disso, ao excepcionar da incidência do art. $2^{\circ}$ e seus incisos somente os cultos e liturgias de matriz africana, a norma do parágrafo único do CEPA, acrescida pela Lei 12.131/2004, violou o princípio da isonomia e o princípio do Estado laico, haja vista que também outras crenças praticam o sacrifício de animais em rituais ou exercício de culto.

Aqui, concentro-me na seguinte questão: a inconstitucionalidade da norma impugnada, inicialmente em ADI perante o Tribunal de Justiça do Estado do Rio Grande do Sul e depois por meio de recurso extraordinário perante o STF, implica a proibição do sacrifício dos animais em liturgias e cultos, seja de matriz africana, seja de outra origem ou matriz? A resposta é negativa. Nenhuma norma do art. $2^{\circ}$ proíbe o sacrifício ou abate de animais. $\bigcirc$ Tribunal de Justiça afirma esse dado normativo, mas, surpreendentemente, o ignora na conclusão a que chega. $\bigcirc$ Tribunal poderia ter declarado a inconstitucionalidade da norma, sem comprometer o direito de credos ou religiões não somente os de matriz africana sacrificarem animais em cultos ou liturgias. Esse mesmo equívoco foi 
cometido em maior grau pelo ministro Edson Fachin, ao votar pela total improcedência do pedido, e em menor grau pelo ministro Marco Aurélio, ao votar pela improcedência parcial. As conclusões a que chegam tanto o Tribunal de Justiça como os ministros do STF, à luz de uma reconstrução argumentativa que adote o postulado da coerência (logicidade), partem da suposição de que a declaração de inconstitucionalidade da norma estadual impugnada implicaria proibir o sacrifício de animais em rituais religiosos.

Por qualquer critério ou técnica de interpretação que se adote, não é possível concluir que as normas do art. $2^{\circ}$ do CEPA proíbem o sacrifício de animais em cultos e liturgias. O propósito dessas normas é proibir práticas socialmente conhecidas de maus-tratos e crueldade contra animais, vindo ao encontro de normas prescritas também pela Constituição do Brasil.

Ademais, do ponto de vista constitucional, o abate ou sacrifício de animais não está proibido. E embora no âmbito da teoria moral e da teoria da justiça possam haver teorias, teses e argumentos que defendam e justifiquem um direito fundamental à vida dos animais sencientes, é fato reconhecido acima de qualquer dúvida razoável que esse direito subjetivo não está assegurado na Constituição do Brasil.

No contexto da análise desse caso, cite-se também previsão normativa da Secretaria de Defesa Agropecuária do Ministério da Agricultura, Pecuária e Abastecimento (BRASIL, 2000), segundo a qual "11.3. É facultado o sacrifício de animais de acordo com preceitos religiosos, desde que sejam destinados ao consumo por comunidade religiosa que os requeira ou ao comércio internacional com países que façam essa exigência, sempre atendidos os métodos de contenção dos animais." (grifo nosso).

Em síntese, a declaração de inconstitucionalidade do parágrafo único do art. $2^{\circ}$ do CEPA, introduzido pela Lei 12.131/2004, não afetaria, por si só, o livre exercício de culto, seja de matriz africana, seja de outra matriz ou origem, pela singela razão de que o art. 2 e seus incisos não proíbem o sacrifício ou abate de animais.

O exame crítico até aqui feito seria o suficiente para dar conta do que seria uma resposta constitucionalmente correta ao caso: a declaração de inconstitucionalidade do parágrafo único do art. $2^{\circ}$ do CEPA. No entanto, uma análise crítica do voto do ministro Edson Fachin, em sua globalidade, é uma ótima oportunidade para enfrentar o tema do livre exercício de culto (CB, art. 5, VI e VIII) e da proteção da fauna (CB, art. 225, VII). Trata-se de tema recorrente nos parlamentos (estaduais e municipais), no debate doutrinário e no Poder Judiciário.

No plano substantivo, o voto do ministro Edson Fachin, para fundamentar a decisão de improcedência do pedido, atribui elevado peso ao direito fundamental à liberdade de crença (e consequentemente ao livre exercício de culto) e ao direito à cultura em precedência ao princípio da proteção da fauna e à proibição de maus-tratos e crueldade contra os animais. A exceção (parágrafo único) introduzida no art. $2^{\circ}$ do CEPA resguardaria os direitos fundamentais citados. É certo que na argumentação do ministro Edson Fachin também tem um peso relevante a premissa empírica 
segundo a qual nos rituais religiosos em questão não há maus-tratos ou tratamento cruel, ou ao menos não há tratamento que produza desconforto intolerável ou insuportável aos animais.

Contudo, como já anotado acima, a interpretação do parágrafo único, impugnado pela $\mathrm{ADI}$ e pelo RE, no contexto do art. $2^{\circ}$, ao qual está vinculado, conduz a um resultado claro: reais ou hipotéticos maus-tratos ou práticas cruéis contra animais tipificados nos incisos do art. $2^{\circ}$ do CEPA não são proibidos aos cultos e liturgias de matriz africana, sendo irrelevante argumentar que conforme informações disponíveis, de fato, esses maus-tratos e práticas cruéis não ocorrem. Nesse contexto, declarar a constitucionalidade do parágrafo único implica dar prevalência ao direito fundamental de liberdade de crença e livre exercício de culto e, como também aponta o ministro Edson Fachin, ao direito fundamental à cultura.

Ao invocar o direito à cultura ou à manifestação cultural como fundamento constitucional para afastar a aplicação do inciso VII do art. 225, o ministro Edson Fachin rompe com a jurisprudência do STF firmada no caso da Farra do Boi (RE 153.531), no caso das Rinhas de Galo (ADI 2514, ADI 3776 e ADI 1856) e no caso das Vaquejadas (ADI 4983). Nesses casos, o STF afirmou reiteradamente a prevalência da proibição de maus-tratos e de tratamento cruel contra os animais ante o exercício de práticas culturais, mesmo que de longa e enraizada tradição popular.

Os direitos à liberdade de crença e de exercício de culto afastam a aplicação dos mandamentos de proibição de maus-tratos e de tratamento cruel contra animais? Essa pergunta remete à interpretação do âmbito de proteção desses direitos, ou seja, ao seu conteúdo e alcance.

Aqui, adoto a tese segundo a qual os direitos à liberdade de crença e livre exercício de culto são normas principiológicas no sentido da teoria dos princípios de Alexy (2008, cap. 3). Princípios são mandamentos de otimização a serem realizados gradualmente segundo as possibilidades fáticas e jurídicas. O sentido e o alcance desses direitos dependem, em cada caso concreto, das possibilidades fáticas (circunstâncias fáticas do caso) e dos princípios e regras opostos.

No outro polo, está a proibição de maus-tratos e de tratamento cruel contra animais. Dada a elevada densidade ou especificidade semântica do texto, trata-se de norma-regra, portanto, de um mandamento definitivo. Esse dado normativo deve ser interpretado em conexão sistemática com o inciso VII do art. $5^{\circ}$ da CB: "ninguém será privado de direitos por motivo de crença religiosa ou de convicção filosófica ou política, salvo se as invocar para eximir-se de obrigação legal a todos imposta e recusar-se a cumprir prestação alternativa, fixada em lei". Não está no âmbito de proteção do direito fundamental de liberdade de crença religiosa condutas ou comportamentos que caracterizam exclusão ou recusa de obrigação jurídica imposta a todos. É um dever de todos absterem-se de praticar atos omissivos e comissivos de maus-tratos ou de tratamento cruel contra animais. Assim, não integra o âmbito de proteção das liberdades de crença e de exercício de culto práticas de maustratos e de tratamento cruel contra animais.

Considerando-se o caráter de regra (mandamento definitivo) da proibição de maus-tratos e de tratamento cruel contra animais (CB, art. 225, VII) e a interpretação delimitadora do âmbito 
de proteção dos direitos fundamentais à liberdade de crença e de exercício de culto a partir do enunciado normativo do inciso VII do art. $5^{\circ}(\mathrm{CB})$, sequer é necessário realizar-se uma ponderação ou sopesamento de bens.

O argumento do ministro Edson Fachin segundo o qual a estigmatização das crenças, cultos e liturgias de origem africana - fato histórico e sociológico verdadeiro - reforçaria a constitucionalidade da norma do parágrafo único do art. $2^{\circ}$ da CEPA é um argumento sociológico e político, mas não possui referibilidade e relevância normativas para a solução do caso. Reitere-se: não há norma constitucional nem legal que proíbe o sacrifício de animais em cultos e liturgias.

\section{Referências}

ALEXY, Robert. Teoria dos direitos fundamentais. Tradução: Virgílio Afonso da Silva. São Paulo: Malheiros, 2008.

BRASIL. Ministério da Agricultura, Pecuária e Abastecimento. Secretaria de Defesa Agropecuária. Instrução normativa $n^{0}$ 3, de 17 de janeiro de 2000. Disponível em: http://www.agricultura.gov. $\mathrm{br} /$ assuntos/sustentabilidade/bem-estar-animal/arquivos/arquivos-legislacao/in-03-de-2000.pdf. Acesso em: 14 nov. 2018.

RIO GRANDE DO SUL. Decreto n. 43.252, de 22 de julho de 2004. Regulamenta o artigo $2^{\circ}$ da Lei 11.915, de 21 de maio de 2003, que institui o Código Estadual de Proteção aos Animais. Disponível em: <http://www.al.rs.gov.br/legis/M010/M0100099.ASP?Hid_Tipo=TEXTO\&Hid_TodasNormas $=47826 \&$ hTexto $=\&$ Hid_IDNorma $=47826>$ Acesso em: 12 nov. 2018.

RIO GRANDE DO SUL. Lei n. 11.915, de 21 de maio de 2003. Institui o Código Estadual de Proteção aos Animais, no âmbito do Estado do Rio Grande do Sul. Disponível em: http://www.al.rs.gov. $\mathrm{br} /$ legiscomp/arquivo.asp? Rotulo=Lei $\% 20 \mathrm{n} \%$ BA\%2011915\&idNorma $=32 \&$ tipo $=$ pdf. Acesso em: 12 nov. 2018.

RIO GRANDE DO SUL. Lei n. 12.131, de 22 de julho de 2004. Acrescenta parágrafo único ao artigo $2^{\circ}$ da Lei $n^{\circ}$ 11.915, de 21 de maio de 2003, que institui o Código Estadual de Proteção aos Animais, no âmbito do Estado do Rio Grande do Sul. Disponível em: http://www.al.rs.gov.br/filerepository/ replegis/arquivos/12.131.pdf Acesso em: 12 nov. 2018.

RIO GRANDE DO SUL. Supremo Tribunal Federal (Pleno). Recurso Extraordinário 494.601. Relator: Voto do Ministro Marco Aurélio, 9 de agosto de 2018a. Disponível em: https://www.jota.info/wp-content/uploads/2018/08/853cb2cd9a2d25be3f92005203fc3923.pdf?x48657. Acesso em: 13 nov. 2018.

RIO GRANDE DO SUL. Supremo Tribunal Federal (Pleno). Recurso Extraordinário 494.601. Voto do Ministro Edson Fachin, 9 de agosto de 2018b. Disponível em: https://www.jota.info/wp-content/ uploads/2018/08/ec6bf4dd0c3c55df78b032206443ed4e.pdf?x48657. Acesso em: 13 nov. 2018.

RIO GRANDE DO SUL. Tribunal de Justiça. Ação Direta de Inconstitucionalidade 70010129690. Relator: Desembargador Araken de Assis, 18 de abril de 2005. Disponível em: http://www1.tjrs.jus.br/ site_php/consulta/consulta_processo.php?nome_comarca $=$ Tribunal +de + Justi $\% E 7 a \& v e r s a o=\&-$ versao_fonetica $=1 \&$ tipo $=1 \& i d \_c o m a r c a=700 \&$ num_processo_mask=70010129690\&num_pro-

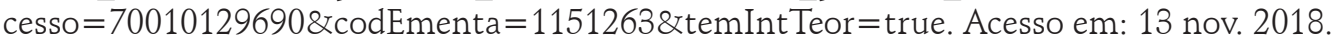


